American Journal of Applied Sciences 4 (4): 203-210, 2007

ISSN 1546-9239

(C) 2007 Science Publications

\title{
Simulation of Aorta Artery Aneurysms Using Active Electronic Circuit
}

\author{
${ }^{1}$ Kamran Hassani, ${ }^{2}$ Mahdi Navidbakhsh and ${ }^{3}$ Mostafa.Rostami \\ ${ }^{1}$ Department of Biomedical Engineering, Amirkabir University of Technology, Tehran, Iran \\ ${ }^{2}$ Department of Mechanical Engineering, Iran University of Science and Technology,Tehran, Iran \\ ${ }^{3}$ Department of Biomedical Engineering, Amirkabir University of Technology, Tehran, Iran
}

\begin{abstract}
The fusiform and saccular aneurysms in different aorta artery sections were studied using an electronic circuit of cardiovascular system. The geometrical model of each artery section including thoracic and abdominal were generated in accordance with original anatomical data. By increasing the rate of aneurysm in each studied section, the pressure drop were calculated using CFD method, furthermore the compliance variations due to aneurysms were determined by mathematical method. The equivalent electronic circuit was then used to study the effects of the pressure drops and compliance variations on whole cardiovascular system. The results of the simulation exhibited the features of the pathology, including hypertension, the increase of the pulse pressure with the rate of aneurysm and the large magnitude of back flow during systole. Finally, the obtained results were compared with relevant clinical data. We have concluded from the study that aorta aneurysms in both fusiform and saccular, especially at highest diameters, may be the most important determinant of the artery rapture and heart failure.
\end{abstract}

Keywords: Aneurysm, aorta, electronic circuit, simulation, CFD, cardiovascular system

\section{INTRODUCTION}

Aortic aneurysm is a degenerative disease, which is defined as focal or diffuse dilatation of the aorta usually caused by arteriosclerosis. Most of aorta aneurysms are fusiform (concentric radial dilatation) but infrequently may be saccular (concentric radial dilatation). The method of modeling the cardiovascular system has previously been applied to the study of system pathologies by a number of authors ${ }^{[1-5]}$. These studies can be grouped loosely into two approaches: highly idealized models which are concerned with a simple cardiovascular system and very complex models which have attempted to predict the detailed behavior of cardiovascular system and one special pathology. In the more complex models, it is impossible to combine mechanical and electrical characteristics and different types of disorders can not be studied. In this study, we have taken a slightly different approach to the modeling of cardiovascular disorders and tried to exhibit the effects of aorta aneurysms on the cardiovascular system using combination of haemodynamics and electrical parameters. We have tried to advance existing models by dividing aorta to different sections in order to study the pathology accurately, meanwhile the arterial system of the model are more detailed. Firstly, We modeled the cardiovascular system with an equivalent circuit and active elements ${ }^{[6]}$ to enable us to show the normal and abnormal operation of the system then, in order to study the influence of aorta aneurysms, the geometry of different section of the artery including abdominal and thoracic were generated. The pressure drops which are caused by aneurysms were determined using CFD method. The compliance variations in the aorta section with aneurysm were also determined by mathematical method. We then alter the haemodynamic parameters including pressure and compliance to their electrical counterparts, voltage and capacity, to explore the effects of the disorder on the presented electronic circuit.

The aorta aneurysm has primarily been studied and the earliest study was by Long $^{[7]}$ and Morris-Stiff ${ }^{[8]}$ who studied the compliance of aorta with aneurysm and observed the effects of aneurysm clinically. More recent studies have used clinical data to investigate the aorta aneurysm ${ }^{[9-11]}$. All of these studies were compared to our model results. Our aim was to introduce a model which shows the aorta aneurysm effects and could address the disorder and do not suggest that the results of our calculations and simulation provided an ideal

Corresponding Author: $\quad$ Kamran Hassani, Department of Biomedical Engineering, Amirkabir University of Technology, Tehran, Iran 
approach, but we do believe that the model can be used in study of many pathologies such as aneurysms or stenosis.

\section{MATERIALS AND METHODS}

Model simulation principles: This study has been conducted in biomedical engineering laboratory of Amirkabir University since 2005. We have used two separate method of simulation. First using CFD method, the pressure drops of each section with respect to different aneurysm sizes are obtained and the compliances are calculated as well. The diameter and length of different aorta sections including abdominal and thoracic have been obtained from the medical texts ${ }^{[12]}$ and $^{[13]}$. The aneurysm with different sizes have been located in the middle of each section because surgical observations confirm that most fusiform and saccular aneurysms occur in the area which is near to middle of the artery, furthermore saccular aneurysms occur mostly in abdominal section but fusiform aneurysms occur both in abdominal and thoracic sections ${ }^{[14]}$. The blood flow has been assumed to be laminar, Newtonian, incompressible and pulsatile. Since aorta is a big artery therefore the blood flow is always considered to be incompressible with constant density ${ }^{[1]}$. The applied pulsatile flow Which has been extracted from experimental data $^{[2]}$ is according to Equation (1):

$Q=1.05+2.407$ Sin $(6.283 t+0.552)+2.324 \quad$ Sin (12.566t-1.096) -0.921 $\operatorname{Sin}(18.849 t+0.7384)$ $-0.398 \operatorname{Sin}(25.132 t-0.082)$

The unit of flow (Q) is $\mathrm{ml} / \mathrm{s}$ and the degrees are according to radian. Using this equation, one $\mathrm{C}$ program file has been written for each section to enable software to apply appropriate unsteady velocity profile to the inlets. By dividing flow to each artery section area, the inlet pulsatile velocity of each section can be calculated. In the next part, the compliance of aorta in both healthy and abnormal conditions is determined. The compliance of a elastic vessel with certain diameter and length is calculated ${ }^{[2]}$ according to Equation (2): $C=\left(3 \Pi \cdot r^{3} \cdot Z\right) / 2 E h$

In this Equation, (r) is radius of the vessel, ( $\mathrm{Z}$ ) length, (E) elastic module and (h) is the thickness of the vessel. The Compliance of aorta in healthy condition can be calculated by Equation (2). In order to determine the compliance of each aorta section with aneurysm, first the relation of (r) and $(\mathrm{Z})$ shall be determined by Equation (3) for saccular aneurysms and Equation (4) for fusiforms:

$r(x)=a x^{2}+b x+c$ $r(x)=a \operatorname{Sin}(\Pi \mathrm{x})+\mathrm{b}(4)$

The $\mathrm{a}, \mathrm{b}$ and $\mathrm{c}$ parameters can be determined for each size of aneurysm in different aorta sections. The compliance of the abnormal aorta sections is calculated by integration of Equation (2) with respect to Equation (3) or (4). The limits of the integral are the points in which the aneurysm starts and ends on each studied aorta section. It shall be noted that abdominal aorta has been divided into three sections of I, II and III as well as thoracic aorta which is divided into two sections of I and II. The pressure drops, and compliance values of aorta sections are determined and calculated individually.

System description: Using CFD method, the pressure drops for different sections of the abdominal I, abdominal II, abdominal III, thoracic I and thoracic II have been calculated. The Geometrical model of each section (with aneurysm located in the middle) have been made. The diameter of aneurysm has been increased from $20 \%$ to $90 \%(20,40,50,70$ and 90 percent) for each vessel section and pressure drops of the section has been determined both for fusiform and saccular conditions. The outlet pressure of each model is considered to be zero and inlet pressure is calculated. The walls of the vessel is non-moving and rigid. This helps us to measure the pressure drops that are only due to blood resistance and not compliance variations. The method of solving is $2 \mathrm{D}$, unsteady, 1 st-order implicit, segregated and axisymmetric. Using CFD method, the pressure graphs and contours of the velocity and pressure have been obtained for each section. In the next part, the compliances in healthy and abnormal conditions are calculated for different aneurysm sizes in different aorta sections. The obtained pressure drops and compliances of the sections with aneurysm are shown in Table 1. The normal values of compliance of abdominal I, II , III, thoracic I and II are $0.1933 \mathrm{ml} / \mathrm{kpa}$ , $0.353 \mathrm{ml} / \mathrm{kpa}, 0.0254 \mathrm{ml} / \mathrm{kpa}, 0.556 \mathrm{ml} / \mathrm{kpa}$ and 0.376 $\mathrm{ml} / \mathrm{kpa}$. The blood flow is considered $83.33 \mathrm{ml} / \mathrm{s}^{[14]}$.

Figure 1 shows the electronic circuit of cardiovascular system ${ }^{[6]}$. This circuit consists of three voltage suppliers which produce required current. There are six resistors, inducers and capacitors which describe the whole aorta artery sections including ascending, thoracic and abdominal. Other parts of system can be seen in the circuit. Voltage, current, charge, resistance and capacitance in the electronic circuit are equivalent to blood pressure, flow, volume, resistance and compliance in the cardiovascular system. Ground potential is equivalent to zero as a reference for voltage measurements. 


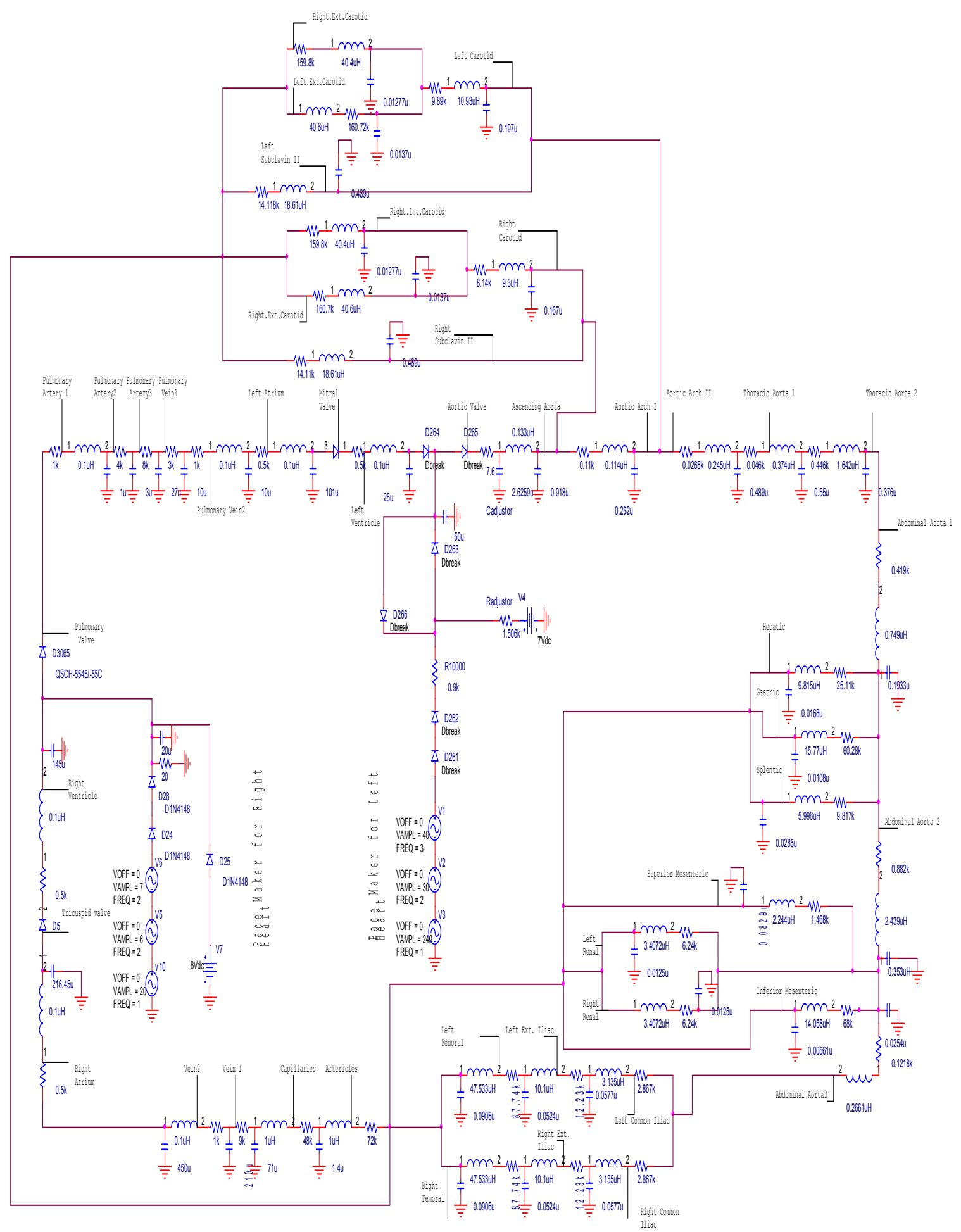

Fig. 1: Electronic circuit of cardiovascular system 
The frequency is $1 \mathrm{~Hz}$ and the correlation between electrical characteristics of the system and their mechanical counterparts are as follow:

$1 \mathrm{mmHg}=1$ volt (pressure $\sim$ voltage)

$1 \mathrm{ml} / \mathrm{pa}=1000 \mu \mathrm{F}$ (compliance $\sim$ capacitance $)$

$1 \mathrm{pa} . \mathrm{s} / \mathrm{ml}=1 \mathrm{k} \Omega$ (resistance)

1 pa. $\mathrm{s}^{2} / \mathrm{ml}=1 \mu \mathrm{H}$ (inertia $\sim$ inducer)

Essentially the energy of systolic contraction is modeled by superposition of three voltage suppliers and diodes. These sources are amplifiers and the input of them are connected to the capacitors and resistors simulating aorta and other arteries. Thus during systole the voltage from the adjusting capacitor (C) is amplified and applied to other capacitors of the circuit. The pressure drop and the compliance of each studied section are converted to their electrical counterparts which are resistance and capacitance. The values have been applied to the related part on the electronic circuit for studying the effects. Later, the pressure graphs of each studied section is obtained by running the circuit.

\section{RESULTS}

The pressure drops of different aorta sections with aneurysm have been determined and shown in Table 1. As it can been seen, the range of pressure drops that have calculated for each section does not show significant difference among the obtained values. The graph of pressure-time for saccular aneurysm of abdominal III (90\%) as well as its pressure contour are shown in Fig. 2 and 3. The pulsatile curve of Fig. 2 has the systolic pressure of 100 pascal which is referred to pressure drops due to Aneurysm of abdominal aorta III in saccular form. The graph mimics the Equation 1 accurately, applied to inlet of the vessel. The pressure distribution of Abdominal III aneurysm with 90 percent diameter can be seen in Fig. 2 where the pressure decreases with distance away from the inlet, the shape of saccular aneurysm can also be observed in the figure. During the simulation, the back flow was seen in the outlet of the vessels due to aneurysm. It shall be noted that CFD method has only used to calculate the pressure drops due to aneurysm and flow analysis has not done in this study. The similar graphs for thoracic I aneurysm in fusiform have been shown in Fig. 4 and Fig. 5.The uniform shape of fusiform aneurysm can be compared with saccular. As it can be understood from the pressure graph of this section, the pressure drop in systolic phase in near to 25 pascal but other results are similar to previous one. The total results regarding pressure drops and compliance variations are listed in Table1.

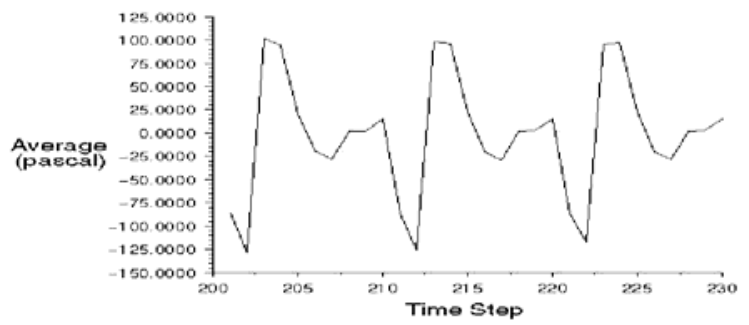

Fig. 2: Pressure graph of abdominal III saccular aorta aneurysm with $90 \%$ diameter increase

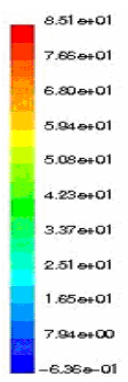

Fig. 3: Pressure contour of saccular abdominal III aorta aneurysm with $90 \%$ diameter increase

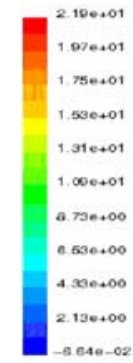

Fig. 4: Pressure contour of fusiform thoracic I aorta aneurysm with $50 \%$ diameter increase

The pressure drops in all section decrease with increase of aneurysm diameter as compliance increases with the rate of aneurysm diameter. The Fig. 6-9 indicate the pressure graphs which have been obtained from the electronic circuit. The relating results have been included in the Table 1 in the Diastol/Systol section , last two columns. The graphs have been obtained by running the circuit after changing of parameters in the relevant parts of aorta section. Reviewing the Fig. 6-9, We understand the increase of systolic and diastolic pressures with the rate of aneurysm

Comparing to normal condition (Fig. 6). These pulsatile pressure-time graphs imply that normal systolic pressure of $120 \mathrm{mmHg}$ (volt) has been increased gradually as well as diastolic. 
Am. J. Applied Sci., 4 (4): 203-210, 2007

Table 1: Values of pressure drops, calculated compliances and final Diastolic/Systolic pressures of different sections of Aorta affected by Aneurysm both in fusiform and saccular shapes. Please note that the Diastolic/Systolic pressures are approximate

\begin{tabular}{|c|c|c|c|c|c|c|}
\hline $\begin{array}{l}\text { Abdominal I } \\
(\mathrm{Dia}=12.2 \mathrm{~mm} \text {, } \\
\mathrm{L}=63 \mathrm{~mm})\end{array}$ & $\begin{array}{l}\Delta \mathrm{P}_{\text {systole }}(\mathrm{pa}) \\
\text { (fusiform) }\end{array}$ & $\begin{array}{l}\mathrm{C}_{\text {aneurysm }}(\mathrm{ml} / \mathrm{kpa}) \\
\text { (fusiform) }\end{array}$ & $\begin{array}{l}\Delta \mathrm{P}_{\text {systole }} \text { (pa) } \\
\text { (saccular) }\end{array}$ & $\begin{array}{l}\mathrm{C}_{\text {aneurysm }}(\mathrm{ml} / \mathrm{kpa}) \\
\text { (saccular) }\end{array}$ & $\begin{array}{l}\text { Diastol/Systole } \\
\text { Pressure(mmHg) } \\
\text { (fusiform) }\end{array}$ & $\begin{array}{l}\text { Diastol/Systole } \\
\text { Pressure }(\mathrm{mmHg}) \\
\text { (Saccular) }\end{array}$ \\
\hline $20 \%$ Aneurysm & 70.34 & 0.212 & 84.3 & 0.1985 & $55-150$ & $55-155$ \\
\hline $40 \%$ Aneurysm & 69.9 & 0.302 & 79 & 0.2038 & $55.2-149.7$ & $55.3-154$ \\
\hline $50 \%$ Aneurysm & 69 & 0.36 & 76.4 & 0.22836 & $56-149.2$ & $55.2-153$ \\
\hline $70 \%$ Aneurysm & 65 & 0.504 & 74.6 & 0.28677 & $56.8-148.7$ & $56.1-152.1$ \\
\hline $90 \%$ Aneurysm & 59.5 & 0.692 & 74.1 & 0.3587 & $58-148$ & $56.8-151$ \\
\hline $\begin{array}{l}\text { Abdominal II } \\
(\mathrm{Dia}=11.7 \mathrm{~mm}, \\
\mathrm{L}=116 \mathrm{~mm})\end{array}$ & $\begin{array}{l}\Delta \mathrm{P}_{\text {systole }}(\mathrm{pa}) \\
\text { (fusiform) }\end{array}$ & $\begin{array}{l}\mathrm{C}_{\text {aneurysm }}(\mathrm{ml} / \mathrm{kpa}) \\
\text { (fusiform) }\end{array}$ & $\begin{array}{l}\Delta \mathrm{P}_{\text {systole }} \text { (pa) } \\
\text { (saccular) }\end{array}$ & $\begin{array}{l}\mathrm{C}_{\text {aneurysm }}(\mathrm{ml} / \mathrm{kpa}) \\
\text { (saccular) }\end{array}$ & $\begin{array}{l}\text { Diastol/Systole } \\
\text { Pressure(mmHg) } \\
\text { (fusiform) }\end{array}$ & $\begin{array}{l}\text { Diastol/Systole } \\
\text { Pressure } \\
\text { (Saccular) }\end{array}$ \\
\hline $20 \%$ Aneurysm & 83.4 & 0.4785 & 87.9 & 0.4454 & $58-158$ & $57-156$ \\
\hline $40 \%$ Aneurysm & 75.73 & 0.805 & 85 & 0.5678 & $60-155$ & $59-155$ \\
\hline $50 \%$ Aneurysm & 74.8 & 1.0 & 84.2 & 0.6438 & $62-152$ & $60-154$ \\
\hline $70 \%$ Aneurysm & 62.4 & 1.385 & 83 & 0.745 & $64-148$ & $61.5-152$ \\
\hline $90 \%$ Aneurysm & 61.5 & 2.55 & 82.1 & 1.0625 & $70-147$ & $63-150$ \\
\hline $\begin{array}{l}\text { Abdominal III } \\
(\mathrm{Dia}=10.4 \mathrm{~mm} \text {, } \\
\mathrm{L}=10 \mathrm{~mm})\end{array}$ & $\begin{array}{l}\Delta \mathrm{P}_{\text {systole }}(\mathrm{pa}) \\
\text { (fusiform) }\end{array}$ & $\begin{array}{l}\mathrm{C}_{\text {aneurysm }}(\mathrm{ml} / \mathrm{kpa} \text { ) } \\
\text { (fusiform) }\end{array}$ & $\begin{array}{l}\Delta \mathrm{P}_{\text {systole }} \text { (pa) } \\
\text { (saccular) }\end{array}$ & $\begin{array}{l}\mathrm{C}_{\text {aneurysm }}(\mathrm{ml} / \mathrm{kpa}) \\
\text { (saccular) }\end{array}$ & $\begin{array}{l}\text { Diastol/Systole } \\
\text { Pressure(mmHg) } \\
\text { (fusiform) }\end{array}$ & $\begin{array}{l}\text { Diastol/Systole } \\
\text { Pressure } \\
\text { (Saccular) }\end{array}$ \\
\hline $20 \%$ Aneurysm & 70.4 & 0.225 & 114 & 0.03184 & $55-151$ & $55-163$ \\
\hline $40 \%$ Aneurysm & 69.6 & 0.3099 & 110 & 0.0406 & $54-150$ & $56-161$ \\
\hline $50 \%$ Aneurysm & 69.1 & 0.362 & 105 & 0.04603 & $53.8-149.7$ & $57-160$ \\
\hline $70 \%$ Aneurysm & 64 & 0.489 & 100.8 & 0.0592 & $52-148$ & $59-159.2$ \\
\hline $90 \%$ Aneurysm & 58.37 & 0.65 & 97.6 & 0.07605 & $55-146$ & $60-158.3$ \\
\hline $\begin{array}{l}\text { Thoracic I } \\
(\mathrm{Dia}=20 \mathrm{~mm}, \\
\mathrm{L}=52 \mathrm{~mm})\end{array}$ & $\begin{array}{l}\Delta \mathrm{P}_{\text {systole }}(\mathrm{pa}) \\
\text { (fusiform) }\end{array}$ & $\begin{array}{l}\mathrm{C}_{\text {aneurysm }}(\mathrm{ml} / \mathrm{kpa}) \\
\text { (fusiform) }\end{array}$ & $\begin{array}{l}\Delta \mathrm{P}_{\text {systole }} \text { (pa) } \\
\text { (saccular) }\end{array}$ & $\begin{array}{l}\mathrm{C}_{\text {aneurysm }}(\mathrm{ml} / \mathrm{kpa}) \\
\text { (saccular) }\end{array}$ & $\begin{array}{l}\text { Diastol/Systole } \\
\text { Pressure(mmHg) } \\
\text { (fusiform) }\end{array}$ & $\begin{array}{l}\text { Diastol/Systole } \\
\text { Pressure } \\
\text { (Saccular) }\end{array}$ \\
\hline $20 \%$ Aneurysm & 26.2 & 0.61475 & - & - & $53-135$ & - \\
\hline $40 \%$ Aneurysm & 23.4 & 0.846 & - & - & $54-133$ & - \\
\hline $50 \%$ Aneurysm & 21.9 & 0.9915 & - & - & $56-132.5$ & - \\
\hline $70 \%$ Aneurysm & 21.5 & 1.347 & - & - & $56.5-132$ & - \\
\hline $90 \%$ Aneurysm & 20.66 & 1.7984 & - & - & $59-130$ & - \\
\hline $\begin{array}{l}\text { Thoracic II } \\
(\mathrm{Dia}=13.5 \mathrm{~mm} \text {, } \\
\mathrm{L}=104 \mathrm{~mm})\end{array}$ & $\begin{array}{l}\Delta \mathrm{P}_{\text {systole }}(\mathrm{pa}) \\
\text { (fusiform) }\end{array}$ & $\begin{array}{l}\mathrm{C}_{\text {aneurysm }}(\mathrm{ml} / \mathrm{kpa} \text { ) } \\
\text { (fusiform) }\end{array}$ & $\begin{array}{l}\Delta \mathrm{P}_{\text {systole }} \text { (pa) } \\
\text { (saccular) }\end{array}$ & $\begin{array}{l}\mathrm{C}_{\text {aneurysm }}(\mathrm{ml} / \mathrm{kpa}) \\
\text { (saccular) }\end{array}$ & $\begin{array}{l}\text { Diastol/Systole } \\
\text { Pressure(mmHg) } \\
\text { (fusiform) }\end{array}$ & $\begin{array}{l}\text { Diastol/Systole } \\
\text { Pressure } \\
\text { (Saccular) }\end{array}$ \\
\hline $20 \%$ Aneurysm & 63.7 & 0.505 & - & - & $57-149$ & - \\
\hline $40 \%$ Aneurysm & 51.05 & 0.918 & - & - & $61-147$ & - \\
\hline $50 \%$ Aneurysm & 50.75 & 1.15 & - & - & $61.8-146.5$ & - \\
\hline $70 \%$ Aneurysm & 44.05 & 1.775 & - & - & $66-143.5$ & - \\
\hline $90 \%$ Aneurysm & 42.2 & 2.6259 & - & - & $68-142$ & - \\
\hline
\end{tabular}

The pulse pressure, systolic minus diastolic, have been increased respectively. There is not any unstable peak in the graphs and all waves are in the same level. The hypertension phenomena can be resulted from the graphs meaning that the main effect of aorta aneurysm is increase of blood pressure. It shall be noted that Fig. 6 shows the normal operation of aorta which indicates the pressure variation between $80-120 \mathrm{mmHg}$ (volt). The compliances which have been calculated by Equations and listed in Table 1 imply the increase of compliance with the rate of aneurysm and this is because of diameter increasing in the aneurysms .

\section{DISCUSSIONS AND CONCLUSION}

There is not any direct experimental observation regarding local pressure drops of the aorta aneurysm, furthermore most of the aorta aneurysm occur only in abdominal. The experimental observations have found a positive correlation with systolic pressure but a negative correlation with diastolic pressure of blood ${ }^{[9]}$. This indicates that increasing pulse pressure (systolic minus diastolic) is associated with increased aneurysm expansion rate. The expansion rate increases from 0 to 18 percent of aneurysm diameter per year as pulse pressure increases from 10 to $120 \mathrm{mmHg}^{[9]}$. 


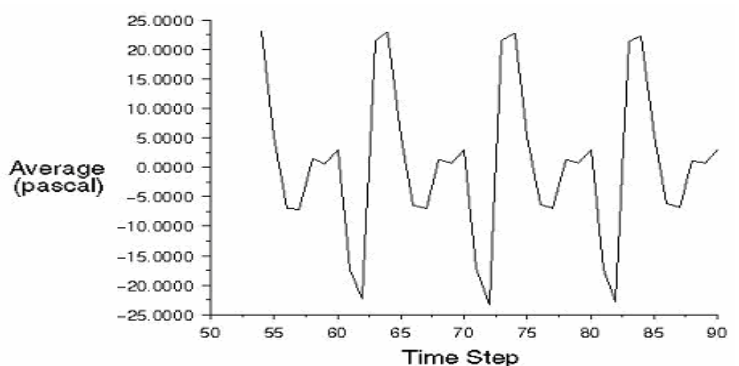

Fig. 5: Pressure graph of fusiform thoracic I aorta aneurysm with $50 \%$ diameter increase

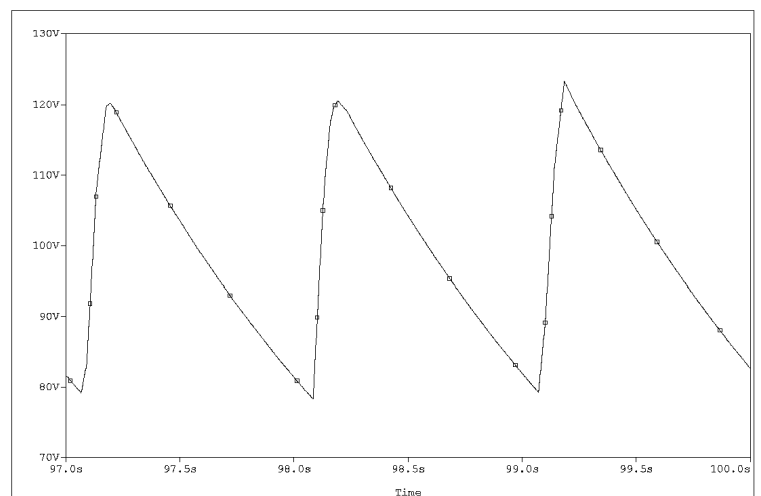

Fig. 6: Pressure graph of normal aorta varying between $80-120$ volt $(\mathrm{mmHg})$

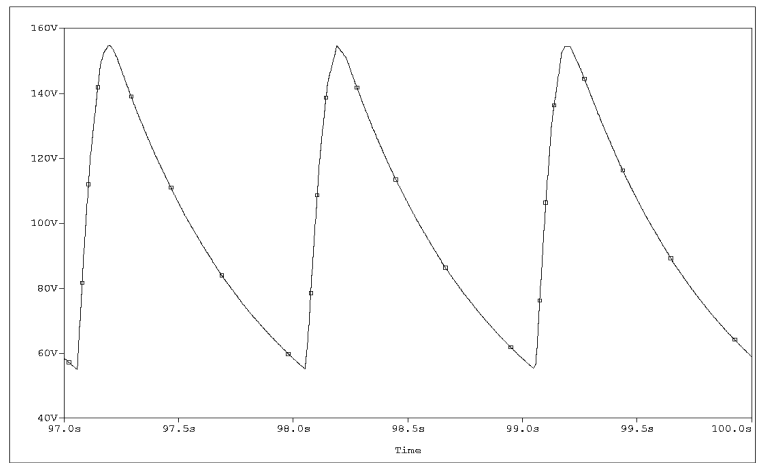

Fig. 7: Pressure graph of saccular abdominal I aorta aneurysm with $20 \%$ diameter increase

Comparing the values of diastolic and systolic pressure of aneurysm aorta which are shown in Table 1 with clinical data confirms the results of simulation. We see hypertension phenomena in all of the studied sections. It is right that aneurysm of aorta causes local pressure drops according to our model or natural condition but the total effects of aorta aneurysm on the cardiovascular is increase of blood pressure due to many other factors such as fibrillin. The most effective factor which controls the hypertension of abdominal aortic is compliance. The results of Table 1 show the compliance

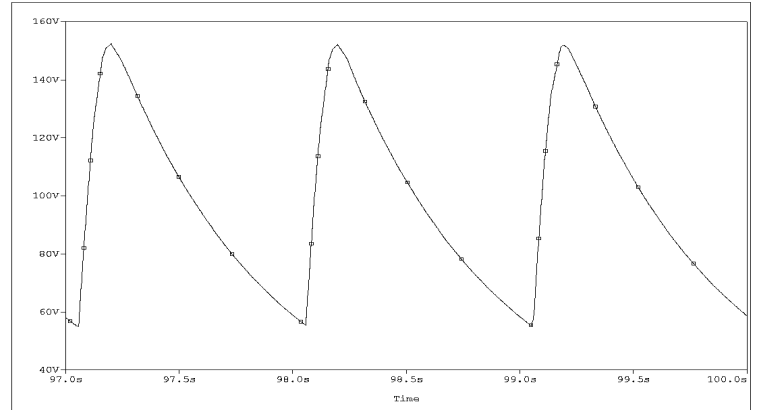

Fig. 8: Pressure graph of saccular abdominal I aorta aneurysm with $70 \%$ diameter increase

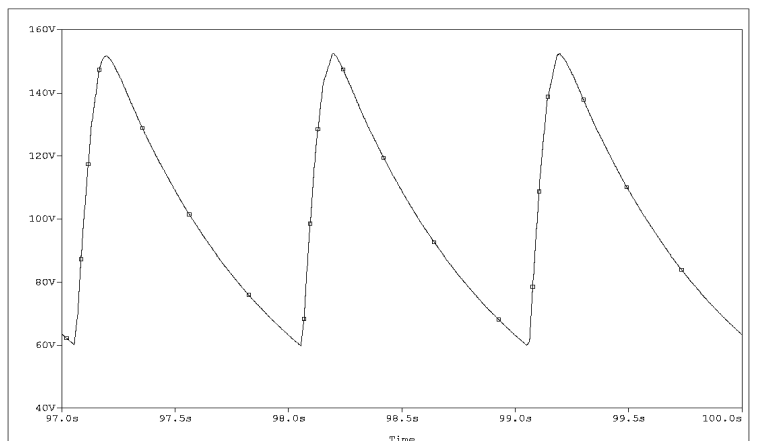

Fig. 9: Pressure graph of fusiform abdominal II aorta aneurysm with $40 \%$ diameter increase.

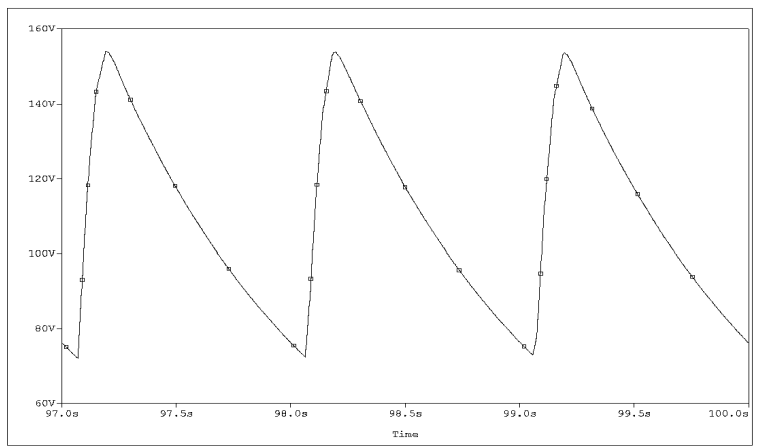

Fig. 10: Pressure graph of fusiform abdominal II aorta aneurysm with $90 \%$ diameter increase

of aneurysm aorta artery comparing to its normal value. For example the compliance of abdominal I aorta in normal condition is $0.1933 \mathrm{ml} / \mathrm{kpa}$ but the it is $0.692 \mathrm{ml} / \mathrm{kpa}$ at the highest diameter of fusiform aneurysm. Using our method of calculation, we have found when the diameter of aneurysm increases, the rate of compliance increases due to increase of diameter for both aneurysm types. The experimental observations show that alerted elastic properties and a 
reduced concentration of aortic elastin both have been associated with abdominal aorta aneurysm. Therefore, genetic parameters and their variations could also affect on the elastic properties of the aorta and an important rule of aneurysm growth. It shall be noted that although elasticity module (E) decreased as a result of aneurysm which means that large aneurysms tended to be less compliant but the relationship is weak ${ }^{[7]}$. The study of 12 patients observed that there was an inverse relationship between maximum diameter of aneurysm, $\mathrm{E}$ and stiffness. The abdominal aneurysm aorta expansion was only associated with a significant increase in $\mathrm{E}$ and stiffness in non operated aneurysm ${ }^{[7]}$. However, the criteria for open repair were not clearly defined. The relationship between E, stiffness and abdominal aorta aneurysm size thus seems to remain complex. The differences in reported results could be related to differences in numbers of patients included in studies as well as methods of statistical analysis. Our method has shown that compliance of aneurysm aorta increased with the rate of aneurysm size growth. This is according to experimental observations ${ }^{[7]}$. Our results show that abdominal I aneurysm of aorta causes the pulse pressure (systole minus diastole) to rise from normal value of $40 \mathrm{mmHg}$ (volt) to average of 96 $\mathrm{mmHg}$. These values are calculated for abdominal II equal to $82 \mathrm{mmHg}$ (volt), $96 \mathrm{mmHg}$ (volt) for abdominal I, $77 \mathrm{mmHg}$ for thoracic I and $85 \mathrm{mmHg}$ for thoracic II. The physiological observations show the total pulse pressure of 52.5 to $120 \mathrm{mmHg}$ for abdominal aortic aneurysms depending on the size of aneurysm $^{[9]}$ and $^{[10]}$ furthermore, there is not any relationship among the pulse pressure of aorta sections because their lengths and diameters are completely different. All other pressure graphs have been obtained for the sections but are not brought here. We can express that our electronic circuit as well as the calculations of the pressure drops and compliances are in good agreement with physiological data. The other experimental data show the association between some genetic factors like fibrillin-I genotype and blood pressure in patients with abdominal aorta aneurysm. In contrast, in this same group of patients there were no associations between blood pressure and the other genetic factors such as the type III collagen. This factor encodes important structural proteins of aortic matrix which causes decrease of compliance. In conclusion, we suggest first that variations in the genetic factors modulates the elastic properties of the aorta to influence arterial pulse pressure and second that in consequence variation of diameter and $\mathrm{E}$ influences the blood pressure which cause hypertension in case of aortic aneurysm. Before drawing conclusions about our results, we would like to reiterate that the goal of this study was to develop a

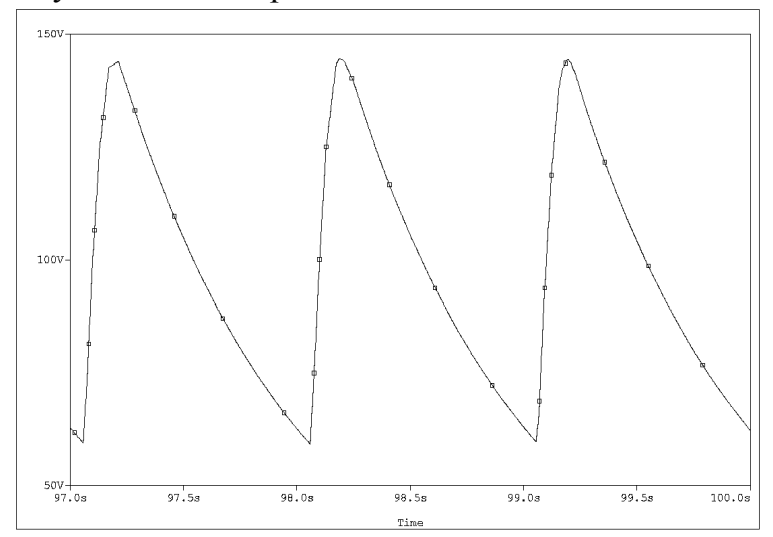

Fig. 11: Pressure graph of fusiform thoracic II aorta aneurysm with $50 \%$ diameter increase

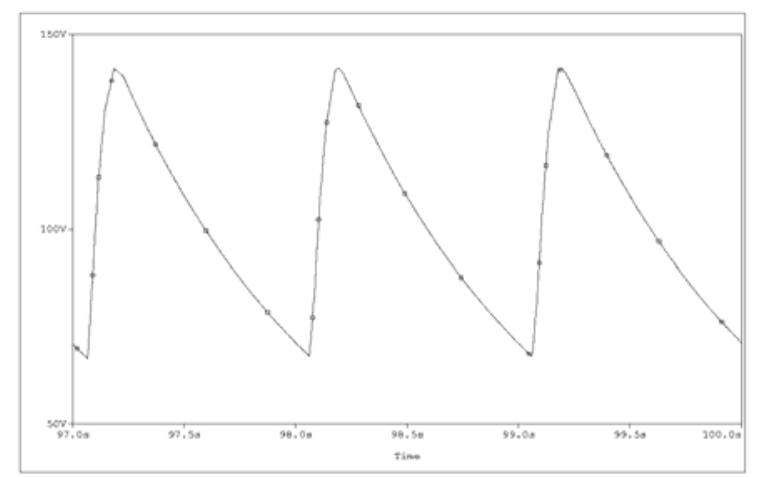

Fig. 12: Pressure graph of fusiform thoracic II aorta aneurysm with $90 \%$ diameter increase

model with which we could explore the influence of aorta aneurysms in whole cardiovascular system. With this goal in mind, we have used a electronic circuit of the cardiovascular system with detailed arterial tree. We have made simplifying assumptions about the nature of the original system, such as rigidity of aorta, but the results of our simulation were successful in presenting the effects of aorta aneurysms. The results of the simulation suggest that aneurysms of aorta in both saccular and fusiform increase the pulse pressure of the arterial system and this phenomena has been observed and investigated in clinical cases. Our conclusion is that the presented model of aneurysm as well as the electronic circuit mimic the original situation accurately but shall be developed with more real limits such as linearity and the model can be useful for students to be more familiar with pathologies of cardiovascular system . 


\section{REFERENCES}

1. Rideout, V.C., 1991. Mathematical and computer modeling of physiological systems. New York: Prentice Hall.

2. Navidbakhsh, M., 1996. Numerical simulation of blood flow in human artery system. Phd thesis, I.N.P.L Luran Polytechnic, France.

3. Migliaavacca, F. and G.E. Cellier, 2001. Modeling of the Norwood circulation: effects of shunt size, vascular resistance and heart. J. Phisiol. Heart Circ. Phisiol., 280: 457-70.

4. Heldet, T. and E. Shim, 2002. Modeling of cardiovascular response to orthostatic stress. J. Appl. Physiol., 92: 1239-54.

5. Rupnic, M. and F. Runvovc, 2002. Simulation of steady state and transient phenomena by using the equivalent electronic circuit. J. Computer Methods and Programs in Biomedici., 67: 1-12.

6. Hassani, K., M. Navidbakhsh and M. Rostami, 2006. Simulation of cardiovascular system using equivalent electronic circuit. J. Biomedical Papers, 150: 105-112.

7. Long, A, L. Rouet and A. Bissery, 2004. Compliance of abdominal aortic aneurysms; evaluation of tissue Doppler imaging . J. Ultrasound in Medical and Biology, 30: 10991108.
8. Morris-Stiff, G., M. Haynes, S. Ogunbiyi, E. Townsend, S. Shetty, R.K. Winter and M.H. Lewis, 2005. Is Assessment of Popliteal Artery Diameter in Patients Undergoing Screening for Abdominal Aortic Aneurysms a Worthwhile Procedure. Eur. J. Vascular and Endovascular Surgery, 30: 71-74.

9. Tilson, M.D. and D.B. Charles, 1996. The abdominal aortic aneurysms. Annals The New York Academy of Science, Vol. 800.

10. Schurink, H., J.M. Baalen and N.J.M. Aars, 2000. Experimental study of the influence of endoleak size on pressure in the aneurysm sac and the consequences. Br. J. Surgery, 80: 71-78.

11. Carmine, M., P. Cappiello, B. Cimmino and M.D. Natale, 2004. New access to facilitate endovascular repair of descending aorta aneurysms. The Annals of Thoracic Surgery, 77: 1445-1447.

12. Guyton, A.C., 1996. Text Book of Physiology. Vol. I. Philadelphia: W.B. Saunders.

13. Wang, J.J. and K.H. Parker, 2004. Wave propagation in a model of the arterial circulation. J. Biomechanics, 37: 457-70.

14. Wilson, K., P. Hoskins and A. Lee, 2000. Ultrasonic measurement of abdominal aortic aneurysm wall compliance: A reproducibility study. Eur. J. Vascular and Endovascular Surgery, 31: 507-513. 